\title{
ESSAY
}

\section{Legitimering van massale schade}

\author{
De narratieve sociologie van Lois Presser
}

Bas van Stokkom

\section{Inleiding}

Lois Presser is een Amerikaans sociologe die zich de laatste jaren veel heeft ingespannen om de narratieve criminologie op de kaart te zetten. Voorafgaand aan haar opleiding werkte ze tien jaar lang met daders en slachtoffers in het strafrechtelijk systeem in New York City. Ze heeft in die periode ook zicht gekregen op de kansen en knelpunten van dader-slachtofferconfrontaties. Ik laat in dit reviewessay haar studies over gewelddadige mannen en kansen op verbetering van hun gedrag buiten beschouwing en zal vooral haar kritisch-criminologische werk onder de loep nemen. Dat werk is samengebald in twee relatief dunne boeken: Why We Harm (2013) en Inside Story: How Narratives Drive Mass Harm (2018). Ze ontwikkelt in die boeken een algemene theorie van schadelijk handelen, in het bijzonder collectieve en massale vormen van schadelijk handelen die veelal gerelateerd zijn aan staatsinstellingen en grote bedrijven, en ze laat zien dat allerlei verhalen, scripts en ideologieën dat handelen goedpraten, ondersteunen, toedekken of ontkennen. In haar analyses zijn cultuursociologie, kritische criminologie en discoursanalyse steeds innig met elkaar vervlochten.

\section{Why We Harm}

Het boekje Why We Harm poogt de culturele logica van schadelijke gedragingen te achterhalen. Op welke wijze dragen scripts en retorische frames bij aan schadelijk handelen? De effecten van dergelijke discoursen worden volgens Presser door mainstream criminologische theorieën over het hoofd gezien. Haar onderzoek is gebaseerd op interviews met gewone burgers, die vertellen hoe zij schadelijke praktijken ondersteunen of bekritiseren, alsmede op eerder gepubliceerde onderzoeken naar het legitimeren van die praktijken. Ze wijdt in Why We Harm vier hoofdstukken aan zeer uiteenlopende vormen van schadelijk handelen - respectievelijk genocide, vlees eten, partnergeweld en de leedtoevoegende straf - en de daarbij behorende stereotyperingen en retorische redeneringen. Voorafgaand aan genocidale oorlogen worden vijanden menigmaal gelabeld als 'vuil' of 'uitschot'. Vleeseters vallen meestal terug op utilitaire termen, in casu de gebruikswaarde van vlees, om gedachten aan dierenleed te ontlopen. Bij mishandeling van vrouwen in thuissituaties speelt vaak het verhaal dat mannen het recht hebben hun vrouw te slaan. Bestraffing door de overheid brengt Presser in verband met de 'power to punish' die in de Verenigde Staten wordt versterkt door het verhaal van 
een 'redeemer nation', een verkozen volk dat het recht heeft om agressie in naam van verlossing toe te staan. 'In order to redeem the world, the chosen people must fight the holy war. They must defeat the forces of evil and chaos' (Presser, 2013: 100). Dat zou kunnen verklaren waarom in dat land relatief weinig vraagtekens worden geplaatst bij het toebrengen van punitieve schade.

Aan het slot van het boek - de synthese - expliciteert Presser de culturele logica die achter al deze vormen van beschadiging schuilgaat: ten eerste de reductie van het doelwit (tot respectievelijk 'vuil', 'vlees', 'hoer' en 'gevaar'), dat wil zeggen de ontkenning van menselijke waardigheid en de beschermwaardigheid van dieren, ten tweede het geloof dat het toebrengen van schade onvermijdelijk is (vaak om controle te houden of te herwinnen), en ten derde de vermeende legitimiteit om schade aan te richten. Wat dat laatste betreft: mensen menen vaak het recht te hebben schade aan te richten. Bijvoorbeeld vanwege hun relatie tot een god, hun verheven plaats in de evolutie, of gewoonweg omdat zij fysiek daartoe uitgerust zijn. Mensen schrijven zichzelf dus macht toe, bijvoorbeeld om (vermeend) onrecht ongedaan te maken. Omgekeerd - en paradoxaal genoeg - kunnen rechtvaardigingen die attenderen op machteloosheid ook bijdragen aan het legitimeren van schade. 'Ik moest wel', 'ik kon niet anders' of 'ik had geen andere keuze'. Zelfverdediging is daarvoor illustratief. Al deze opvattingen projecteren zowel macht als machteloosheid. Beide aspecten zijn constitutief voor schadelijk handelen. In dat verband spreekt Presser over de 'paradox van macht': de onmacht die (vermeende) aantasting van belangen of rechten oproept, geeft het recht om in te grijpen. We gaan daarbij geloven in verhalen die een vijand of tegenstrever construeren. Zo spelen in de context van genocide zowel 'lot' als 'schuld' een grote rol: 'emphasizing fate - bending one's will - and fault - demanding reprisal' (Presser, 2013: 49).

Bij het formuleren van deze algemene theorie is Presser schatplichtig aan neutraliseringstheorieën, en dan vooral David Matza's theorie over 'delinquency and drift'. Een gevoel van onrecht en een subcultureel geloof in het lot genereren een gemoedstoestand van fatalisme die bevestigt dat je geen greep hebt op de omgeving. Denk aan de hulpeloosheid van jonge mannen die in situaties verkeren waarin zij zich niet kunnen bewijzen. Dat kan uitmonden in een gemoedstoestand die Matza 'drift' heeft genoemd, een 'episodic release from moral constraint' waardoor controle kan worden herwonnen (Matza, 1964: 69). Vooral de retoriek die draait om identiteiten - wie zijn we? waar hoor ik bij? - doen het werk om in die gemoedstoestand te geraken. Een andere studie waarnaar Presser in dat verband verwijst. is Charles Tittles theorie van 'control balance' (Tittle, 1995), die immers ook focust op macht en machteloosheid. Deviant gedrag doet zich voor bij een teveel of juist een tekort aan controle, niet in reële maar in subjectieve termen: hoe wordt controle beleefd en waargenomen? Typerend is dat topmanagers zichzelf regelmatig wijsmaken dat hun macht is afgebrokkeld en dat (onwettige) actie is geboden om dat 'tekort' te herstellen en weer controle te krijgen. 


\section{Inside Story}

In Inside Story pakt Presser de draad van Why We Harm op en gaat ze nader in op de vraag wat verhalen hun kracht geeft en hoe ze motiveren om schade toe te brengen of die schade te ontkennen. Ze richt daarbij het vizier op de 'emotional turn' in de sociale wetenschappen en veronderstelt dat verhaal en emotie nauwelijks van elkaar te scheiden zijn. Verhalen hebben niet alleen een legitimerende functie, ze weten ook te prikkelen, inspireren, aan te grijpen en de emotionele temperatuur te verhogen. Daarnaast bespreekt ze het vermogen van verhalen om gemoedsrust te geven en onrecht te laten voor wat het is. Volgens Presser geloven mainstream criminologen nog altijd dat alleen reële zaken (achterstand, tekort aan bindingen, etc.) misdaad veroorzaken, maar schadelijk handelen kan beter als resultante worden gezien van verhalen die ons gemoed beïnvloeden. Het doet er niet toe of een verhaal met de werkelijkheid correspondeert, het is de geloofwaardigheid die telt en die commitment genereert.

Normalerwijs wordt grootschalige en massale schade - oorlog, slavernij, economische uitbuiting, politieke repressie, milieuvervuiling - verklaard in termen van machtsmisbruik, competitie, verwervingsdrang en maximalisering van winst. Volgens Presser is het interessanter te kijken hoe dat handelen symbolisch gecodeerd is: hoe wordt massale schade genormaliseerd, getrivialiseerd, gerechtvaardigd, aanbevolen of verduisterd? Het gaat dus om scripts, codes, verhalen en ideologieën waaraan geloof wordt gehecht of die acceptabel worden geacht (en deel uitmaken van common sense-overtuigingen). In dat verband geeft Presser aandacht aan Bandura's typen van moreel disengagement, van het toedekken van eigen handelen tot het afhouden van reflectie op de gevolgen van handelen of niet handelen, het simpelweg 'niet willen weten' (Bandura, 1999).

Presser sluit Inside Story af met twee hoofdstukken over hegemoniale typen verhalen: underdogverhalen en (neo)liberale verhalen die ons gemoedsrust verschaffen en voorbijlopen aan massale schade. Beide staan diametraal tegenover elkaar. Sommige verhalen weten woede, verbijstering en een gevoel van urgentie op te wekken. Het verhaal van de underdog is daarvoor illustratief: rechtschapen helden zegevieren over de ellende die machtige tegenstanders hebben aangericht. Terroristen verwoorden op retorische wijze dat hun volk of achterban onderdrukt wordt en dat geweld geoorloofd is. Ook de Amerikaanse Droom is een versie van het underdogverhaal: de held moet van ver komen.

Daartegenover staan verhalen die een tevreden gemoedstoestand genereren. Deze verhalen verdienen volgens Presser veel meer aandacht omdat ze brede steun geven aan institutionele vormen van schadeberokkening. Zo weet het verhaal van leedtoevoeging aan veroordeelden het burgerlijke gehoor gerust te stellen: we moeten misdadigers wel opsluiten, ze zijn immers niet meer te redden. Conformistische burgers geloven graag dat zij er een moreel juiste positie op nahouden. In dat verband gaat Presser uitvoerig in op het 'Grand Theory'-verhaal van Gottfredson en Hirschi dat wetsgetrouwe burgers ervan verzekert dat zij aan de goede kant staan. Het aardige is dat Presser als alleenstaande moeder van twee jonge kinderen haar eigen comfortniveau bij dat verhaal onderzoekt. Ze zet uiteen dat het verhaal tegemoetkomt aan de behoefte van het grote publiek om daders zorgvuldig te scheiden van niet-daders. De reductie van de ander bestaat 
dit keer uit termen als 'impulsief', 'korte termijn genoegens' en 'onvermogen te investeren'. De aanbeveling om het vermogen van zelfcontrole te bevorderen bij mensen die tot criminaliteit neigen, sluit aan bij het gevoel van de tevreden burgerij dat 'wij' wel in staat zijn tot uitstel van behoeften: 'wij' zijn zelfredzaam en hebben controle over ons leven, 'zij' vertonen een karaktergebrek. Dat stelt gerust: mensen die antisociaal gedrag vertonen, zijn daarvoor zelf verantwoordelijk en verdienen straf. Het verhaal fungeert dus als een 'identiteitsvehikel voor de goeden onder ons' (zie ook Presser, 2020).

\section{Een late 'narrative turn' in de criminologie}

In een beschouwing over de 'narrative turn' bevestigt Presser (2016) nog eens dat de narratieve criminologie de sociale (re)productie van allerlei verhalen tot onderwerp van studie maakt. Narratieve criminologen richten zich vooral op identiteitsvorming: verhalen zijn in staat onze identiteit aan te scherpen en fungeren als 'vehikels om opgemerkt te worden'. Denk aan jonge mannen die publiekelijk machogedrag etaleren. Maar het gaat volgens Presser vooral om de impact van verhalen; het doet er weinig toe of ze waar of onwaar zijn. De volgende vragen zijn wel van belang: hoe legitimeren verhalen het aanrichten van schade? En: hoe gaan ze deel uitmaken van ieders zelfbeeld? (Presser, 2016).

Presser benadrukt dat mainstream criminologisch onderzoek - anders dan sociologisch onderzoek - doorgaans onverschillig staat ten opzichte van dat zelfbeeld, ook wel 'the acculturated self' genoemd. Het verhaal van de misdadiger is van het begin af aan gewantrouwd: strategisch, sluw, verhullend, etc. Vandaar het devies: blijf bij de feiten. 'We have told ourselves a story of ourselves as detectors of truth about a transgressing few, promoting the good of a conforming majority' (Presser, 2016: 147). Dat zou wel eens kunnen verklaren, vervolgt ze, dat de 'narrative turn' pas vele jaren later in de criminologie zijn intrede deed. Om heel andere redenen pogen veel kritische criminologen - en zemiologen - de 'werkelijke' sociale structuren achter misdaad bloot te leggen - armoede, racisme, en onderdrukking van vrouwen. Vanuit dat perspectief is cultureel onderzoek naar de discursieve aspecten van machtsuitoefening van minder belang dan de materiële vormen van macht en de schadelijke effecten ervan. Maar het gaat volgens Presser nu juist om 'geïnternaliseerde conversaties' die ons handelen bepalen. Om die reden moeten we de taal, het genre en de kenmerken van verhalende communicatie bestuderen, alsmede de sociaal-politieke context ervan.

\section{Criminologie of zemiologie?}

Presser heeft zich ontpopt tot een specifiek type kritisch criminoloog. De focus op wetsovertreding acht ze te nauw en houdt het zicht af van scripts, frames en rationaliseringen die een rol spelen bij georganiseerde vormen van schadelijk handelen. Het gaat dus om patronen van schadelijk handelen gerelateerd aan institutionele contexten, niet om geïsoleerde incidenten tussen personen (Presser \& Sandberg, 2019). Presser schaart zich achter zemiologen als Paddy Hillyard (2004) die ervoor pleiten niet misdaad maar schade te theoretiseren. Ten eerste omdat de definitie van misdaad door een 'bestuurlijke elite' wordt bepaald, terwijl de definitie van schade eerder op ervaringen van slachtoffers berust. Ten tweede 
omdat beleid van misdaadcontrole en -bestraffing zelf schade en aantasting van menselijke waardigheid voortbrengt. Maar volgens Presser kunnen ook vraagtekens bij de zemiologische onderneming geplaatst worden. Wat te doen met neutralisaties van witteboordencriminelen dat zij geen schade hebben veroorzaakt (voorkennis; prijsafspraken) en daarom niets verkeerd hebben gedaan? Wat te doen met bedrijven die nalatig zijn geweest of verantwoordelijkheid afschuiven naar anderen, of zeggen dat de aangebrachte schade niet geïntendeerd is zoals de tabaksindustrie en wapenindustrie claimen? Nog ingewikkelder: wat te doen met het tolereren van schade, zoals blijkt uit het alledaagse wegkijken van milieuvervuiling of ongemoeid laten van dierenleed in de intensieve veehouderij? Wat dat betreft nodigt Presser ons uit kritisch te kijken naar onze neiging om schade weg te rationaliseren.

Presser laat in het midden of we het spoor van de criminologie of zemiologie moeten volgen. Ze lijkt te beseffen dat misdaad en sociale schade geen aparte disciplines verdienen en dat een strijd om een strikte afbakening van die twee alleen verliezers voortbrengt. Het lijkt vruchtbaarder beide te integreren (zie daarvoor Kotzé, 2018). Het mooie van Pressers 'algemene theorie' van collectief schadelijk handelen is dat ze aanzetten geeft voor die integratie, en wel omdat ze voortdurend blijft inzomen op de narratieve legitimering van schadelijk handelen. Haar werk opent deuren om 'illegitiem handelen' als kernconcept van misdaad te beschouwen (zie Rucman, 2019), een bredere definitie die onder meer ook corruptie, uitbuiting en milieuvervuiling omvat. Toegegeven, het is moeilijk om kernbetekenissen van 'illegitiem handelen' te expliciteren en operationaliseren. Gaat het om vormen van benadeling, om aantasting van menselijke potenties of om handelen dat een verlies aan kwaliteit van menselijk leven en de ecologische omgeving met zich meebrengt? (Henry \& Milovanovic, 1996; Tift \& Sullivan, 2001). Maar duidelijk is dat de criminologische discipline zich met dit brede concept wel kan emanciperen van strafrechtelijke begrippen.

\section{Interessante denksporen}

Zoals bekend zijn mainstream criminologen alweer lange tijd op de vlucht voor reflecties over kernbegrippen als misdaad, straf, strafwaardigheid en schade. Daarbij spelen factoren als neoliberale inkapseling van academische arbeid en het aanvlijen tegen beleidsmakers een grote rol. Het vak lijkt te zijn gereduceerd tot een technische discipline voor het beheer van veiligheid (Loader \& Sparks, 2010). Lois Presser heeft niet veel last van dat keurslijf. Ze beoefent in feite een vorm van cultuursociologie die zich toelegt op het bestuderen van collectieve verhalen die schadelijk handelen toedekken, steunen, aanmoedigen of juist tegengaan. Het aantrekkelijke van haar werk schuilt in de brede interdisciplinaire benadering, maar ook in de durf om normatief te theoretiseren. Zo betrekt ze regelmatig filosofische inzichten bij de duiding van schadelegitimeringen. Haar theoretische exercities zijn daarom speels en verfrissend. Ze laat ongelijksoortige concepten convergeren zodat de lezer het gevoel krijgt dat er iets gebeurt. Suf of uitgekauwd academisch geleuter treft de lezer niet aan. De neiging om allerlei vreemdsoortige 
theoretische noties en categorieën bijeen te brengen heeft wel een prijs. Veel van haar teksten zijn overladen, terwijl argumentaties meermaals open einden bevatten. Sommige aspecten van haar theorie staan nog in de steigers.

Dat neemt niet weg dat Pressers kritiek op het criminologische vak hout snijdt. Zo laat ze treffend zien dat het verhaal van Gottfredson en Hirschi wel heel ver af staat van de basale criminologische notie dat in ieder mens een schurk huist. Iedereen is - afhankelijk van de context - vatbaar voor moreel disengagement. Of zoals Matza het heeft verwoord: het criminele wordingsproces heeft vooral te maken met de al te menselijke neiging om scripts van gepersonifieerd onrecht tevoorschijn te toveren om vervolgens over te schakelen naar geoorloofde tegenreacties. Ook mensen met veel zelfcontrole - de harde werker op kantoor of de grote jongen in de bestuurskamer - is daar bedreven in. 'Ik ben benadeeld en mag daarom wel iets terugpakken.' Opnieuw is de paradoxale samenhang van machteloosheid en macht daarvoor kenmerkend.

Met haar analyse van gangbare, hegemoniale verhalen die steun geven aan schadelijk handelen of dat handelen juist ongemoeid laten, zit Presser op een interessant spoor. Zo zouden ook andere bourgeois discoursen kunnen worden onderworpen aan een narratieve analyse, waaronder de mythe van meritocratie. In dat verhaal wordt de meerderheid van goedwillenden - de harde werkers - beloond en de minderheid van onwillenden - de uitvreters en luiwammesen - bestraft. De uitkomst van dat verhaal lijkt op de Grand Theory van Gottfredson en Hirschi: de burgerij kan met een goed geweten instemmen met de bestaande structuur van in- en uitsluiting.

Ten slotte, Presser sluit zowel Why We Harm als Inside Story af met de suggestie dat we meer werk zouden kunnen maken van het ontwikkelen van verhalen die schade, leed en ellende kunnen verminderen. Van belang daarbij is dat dergelijke verhalen authentiek en waarachtig worden vertolkt, zodat sprekers er niet van verdacht kunnen worden een strategisch 'counter narrative' te verwoorden. Ze meent dat herstelrechtelijke ontmoetingen een goed voorbeeld vormen van hoe dat zou kunnen. Die suggestie verdient verdere uitwerking en verfijning. Daarbij zou onder meer aangesloten kunnen worden bij narratieve mediation, een benadering die handelingsruimte creëert om alternatieve verhaallijnen mogelijk te maken, en vooral de iconiseringstheorie, die ontmoeting tussen slachtoffer, dader en andere stakeholders opvat als een transitieritueel waarbij bindende symbolen worden geproduceerd (Zappavigna \& Martin, 2018).

\section{Literatuur}

Bandura, A. (1999). Moral Disengagement in the Perpetration of Inhumanities, Personality and Social Psychology Review 3(3), 193-209.

Henry, S. \& D. Milovanovic (1996). Constitutive Criminology: Beyond Postmodernism, London: Sage.

Hillyard, P. et al. (2004). (eds.). Beyond Criminology: Taking Harm Seriously. London: Pluto.

Kotzé, J. (2018). Criminology or Zemiology? Yes, Please! On the Refusal of Choice Between False Alternatives. In: A. Boukli \& J. Kotze (eds.), Zemiology. Reconnecting Crime and Social Harm (p. 85-106). Cham: Palgrave Macmillan. 
Loader, I. \& R. Sparks (2010). Public Criminology? London: Routledge.

Matza, D. (1964). Delinquency and Drift. New York: Wiley.

Presser, L. (2013). Why We Harm. New Brunswick, NJ and London: Rutgers University Press.

Presser, L. (2016). Criminology and the narrative turn. Crime Media Culture, 12(2): 137-151.

Presser, L. (2018). Inside Story: How Narratives Drive Mass Harm. Berkeley and Los Angeles, CA: University of California Press.

Presser, L. (2019). The Story of Antisociality: Determining What Goes Unsaid in Dominant Narratives. In: J. Fleetwood, L. Presser, S. Sandberg \& T. Ugelvik (eds.), The Emerald Handbook of Narrative Criminology (p. 415-430). Bingley: Emerald.

Presser, L. \& S. Sandberg (2019). Narrative Criminology as Critical Criminology, Critical criminology 27, 131-143.

Rucman, A.B. (2019). What is crime? A search for an answer encompassing civilizational legitimacy and social harm. Crime, Law and Social Change, 72, 211-226.

Tift, L. \& D. Sullivan (2001). A Needs Based, Social Harms definition of Crime, In: S. Henry \& M. Lanier (eds.), What is Crime? Controversies Over the Nature of Crime and What to Do About It (p. 179-203). Lanham: Rowman \& Littlefield.

Tittle, C. (1995). Control Balance: Toward a General Theory of Deviance, Boulder, CO: Westview.

Zappavigna, M. \& J.R. Martin (2018). Discourse and diversionary justice: an analysis of youth justice conferencing, Cham: Palgrave MacMillan. 